\title{
EGU \\ SIT4ME: seismic imaging of mineral-hosting structures in Sotiel-Coronada (Spain)
}

EGU2020-22146

Yesenia Martínez (1,2), Juan Alcalde (1), David Martí (3), Puy Ayarza (2), Mario Ruiz (1), Ignacio Marzán (1), Fernando Tornos (4), Alireza Malehmir (5), Alba Gil (5), Stefan Buske (6), Dirk Orlowsky (7), Imma Palomeras (2), Juan Manuel Pons (8), Juan Carlos Videira (8), Irene De Felipe (1), and Ramon Carbonell (1)

1Salamanca University, Geology, Salamanca, Spain (yesimartinez@usal.es) 2Department of Geology, University of Salamanca, Spain 3Lithica SCCL, Spain

4Institute of Geosciences, CSIC-UCM, Spain
5Department of Earth Sciences, Uppsala University, Sweden

6 Technische Universität Bergakademie Freiberg, Germany 7DMT GmbH \& CO, Germany

8MATSA, Almonaster la Real (Huelva, Spain)

\section{Introduction}

Our society is greatly dependent on raw materials and their ever-increasing demand puts their supply under strong pressure. The European Institute of Innovation and Technology (EIT) with its RawMaterials Programme promotes research and innovation solutions for sustainable mineral exploration (www.rawmaterials.eu). Within this framework, the SIT4ME project, supported by the EIT, aims to develop and assess seismic imaging approaches for mineral exploration within crystalline (hard-rock) environment, at a reduced cost. The SIT4ME project seeks to test the efficiency of different seismic approaches for subsurface imaging including: control and natural source seismic data-sets. Two world-class case studies are being developed in active mine sites (in Sweden and Spain).

3. Processing Geometry
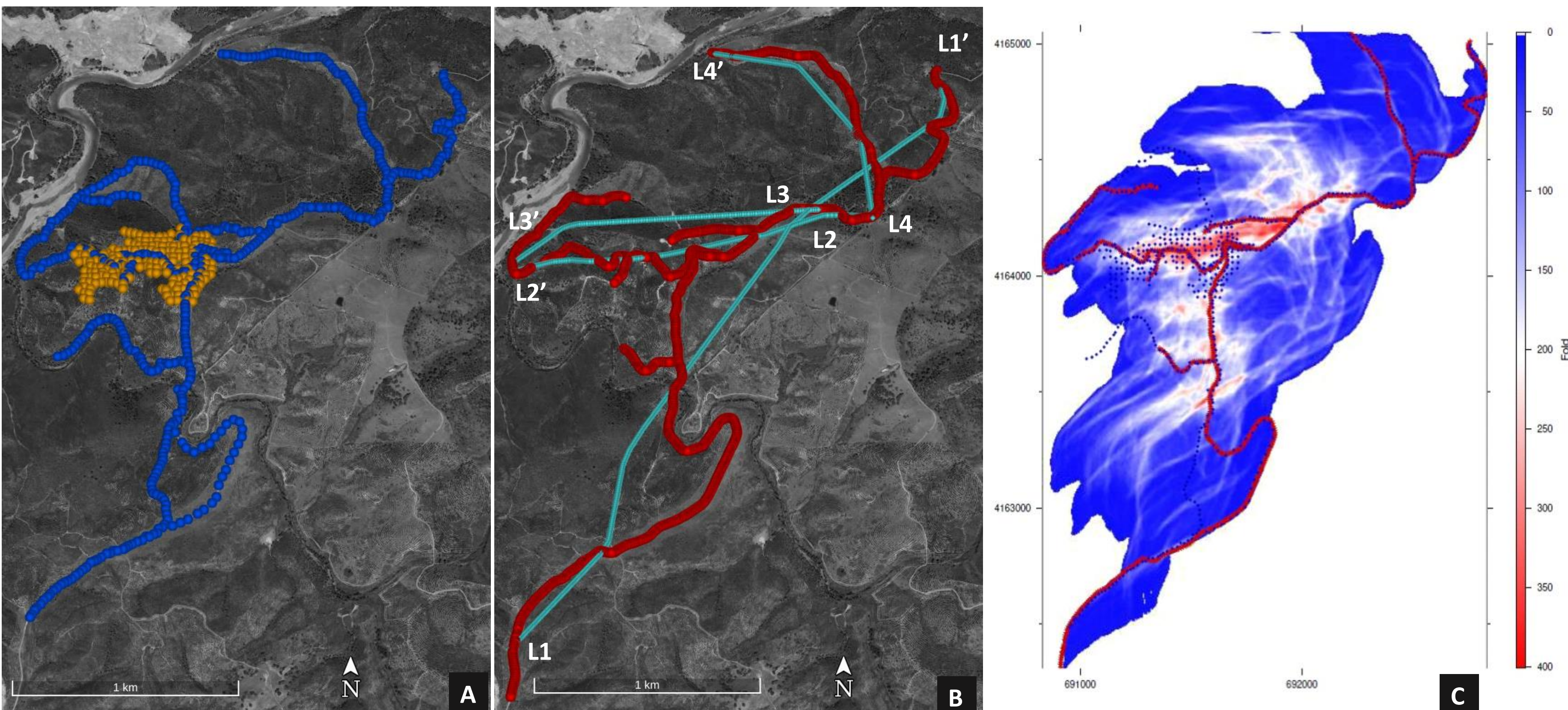

Figure 2: Distribution of the (A) geophones, (B) vibration points across the study area and seismic lines in light blue. (C) CDP fold coverage calculated from a CDP bin size of $5 \mathrm{~m}$.

\begin{tabular}{|ll|}
\hline No. of vibration points & 875 \\
Vibration points spacing & $10 \mathrm{~m}$ \\
Source type & Vibroseis truck (32 t) \\
Sweep length & 15 seconds \\
Frequency range & $10-100 \mathrm{~Hz}$ \\
No. of receiver points & 653 \\
3-component receivers & 247 \\
1-component receivers & 406 \\
Sample rate & $4 \mathrm{~ms}$ \\
Receiver spacing & $20 \mathrm{~m}$ \\
\hline
\end{tabular}

Table 1: Data acquisition parameters

\section{Results}

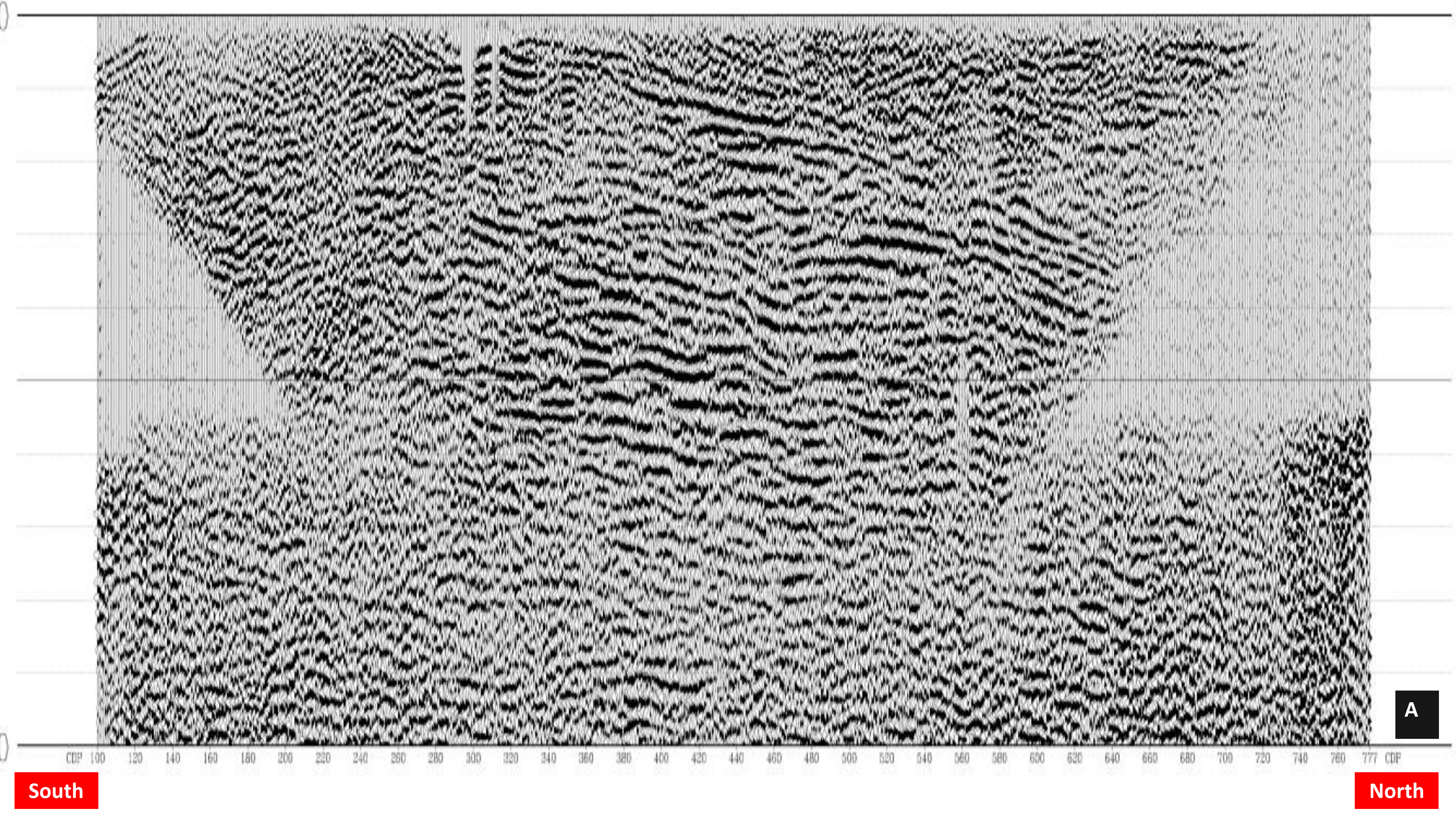

Acknowledgements

The SIT4ME "Seismic Imagin Techniques for Mineral Exploration project is supported by EIT-RawMaterials (17024). The data (DTT G MATSA to be able to access their facility and being able to account with their help.
2. Geological setting

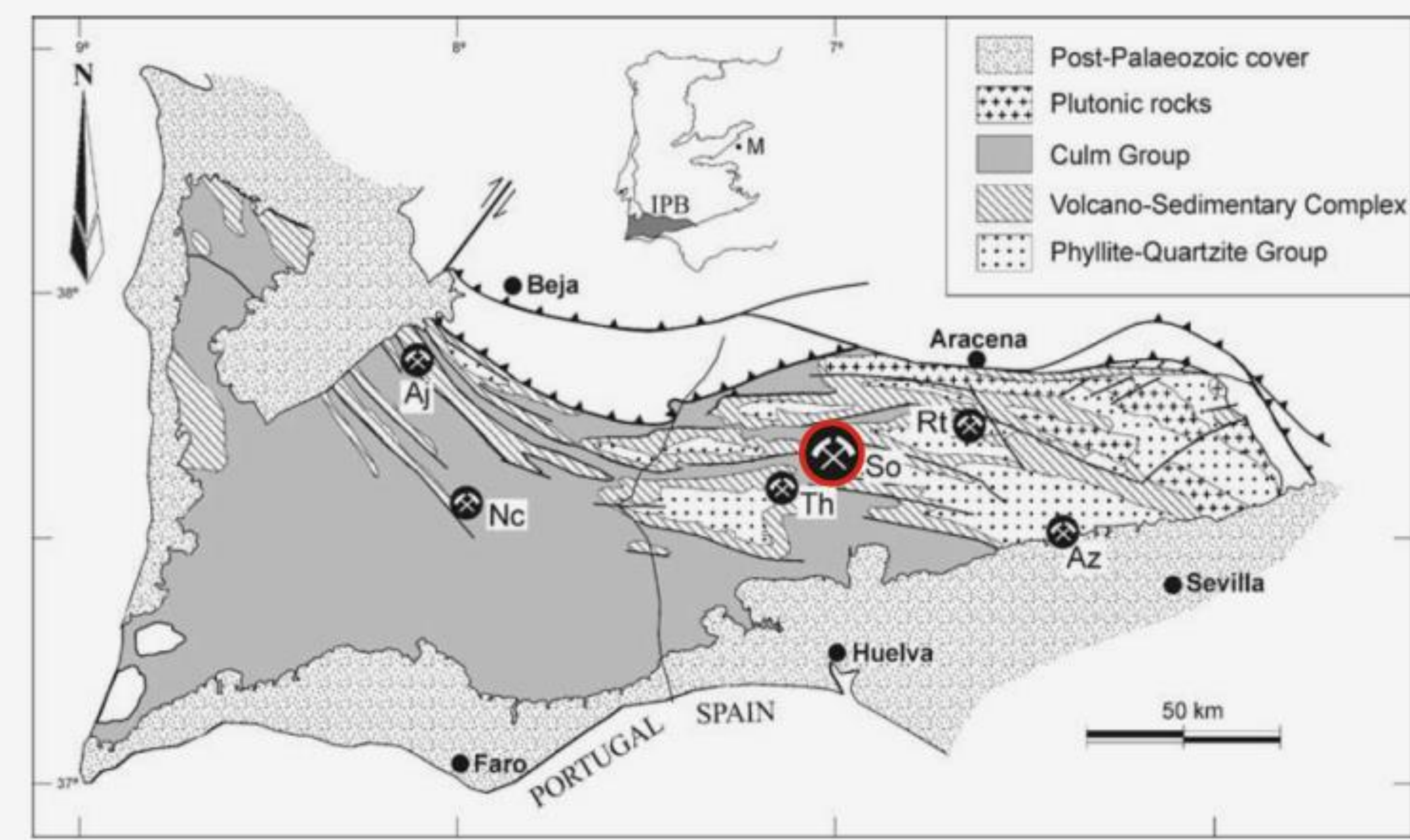

Figure 1: Geological map of the Iberian Pyrite Belt showing the location of the Sotiel Mine and the main mining districts. Gonzalez et al., 2006.

4. Data Processing

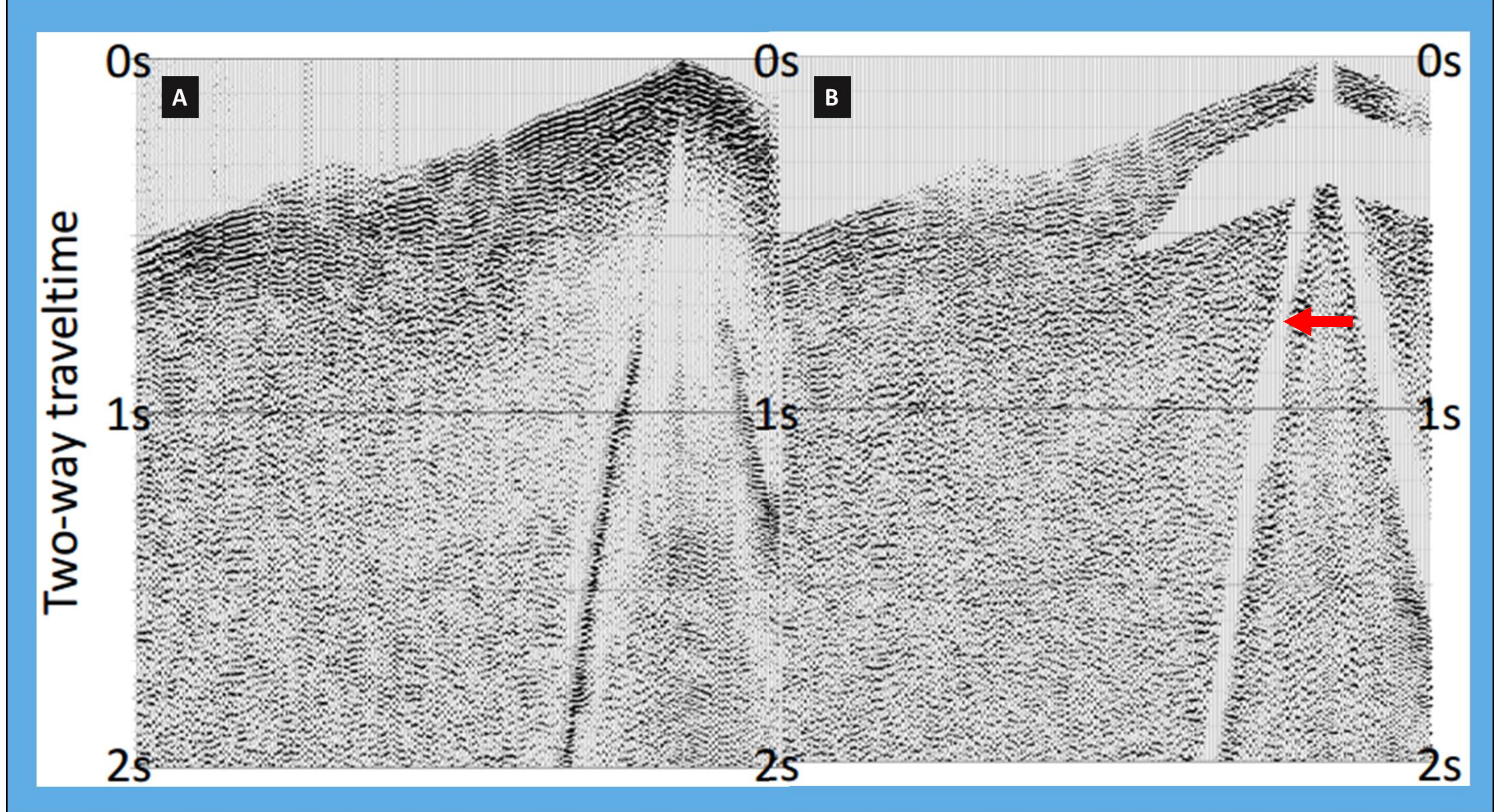

Figure 3: Shot gathers example from L1. A) Raw data and B) processed shot with a reflection marked by a red arrow. The data processing applied consist oy fin: noise trace edition, static corrections (elevation + refraction statics), airy wave mute $(340 \mathrm{~m} / \mathrm{s})$, surgical mute, amplitude equalization, frequency filter $(20-30-65-90 \mathrm{~Hz})$ and notch $(50 \mathrm{~Hz})$. 